\title{
Targeted Multiresidue Method for the Analysis of Different Classes of Pesticides in Agro-Food Industrial Sludge by Liquid Chromatography Tandem Mass Spectrometry
}

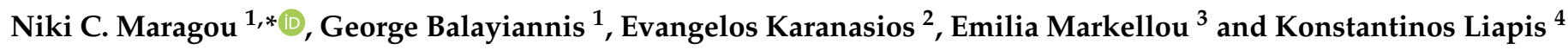 \\ 1 Laboratory of Chemical Control of Pesticides, Scientific Directorate of Pesticides' Control and Phytopharmacy, \\ Benaki Phytopathological Institute, 14561 Athens, Greece; g.balayiannis@bpi.gr \\ 2 Laboratory of Environmental Control of Pesticides, Scientific Directorate of Pesticides' Control \& Phytopharmacy, \\ Benaki Phytopathological Institute, 14561 Athens, Greece; e.karanasios@bpi.gr \\ 3 Laboratory of Mycology, Scientific Directorate of Phytopathology, Benaki Phytopathological Institute, \\ 14561 Athens, Greece; e.markellou@bpi.gr \\ 4 Laboratory of Pesticide Residues, Scientific Directorate of Pesticides' Control and Phytopharmacy, \\ Benaki Phytopathological Institute, 14561 Athens, Greece; k.liapis@bpi.gr \\ * Correspondence: n.maragou@bpi.gr; Tel.: +30-210-8180350
}

\section{check for} updates

Citation: Maragou, N.C.; Balayiannis, G.; Karanasios, E.; Markellou, E.; Liapis, K. Targeted Multiresidue Method for the Analysis of Different Classes of Pesticides in Agro-Food Industrial Sludge by Liquid Chromatography Tandem Mass Spectrometry. Molecules 2021, 26, 6888. https://doi.org/ $10.3390 /$ molecules 26226888

Academic Editors: Thierry Dagnac and Pilar Sandín-España

Received: 14 October 2021

Accepted: 12 November 2021

Published: 15 November 2021

Publisher's Note: MDPI stays neutral with regard to jurisdictional claims in published maps and institutional affiliations.

Copyright: (c) 2021 by the authors. Licensee MDPI, Basel, Switzerland. This article is an open access article distributed under the terms and conditions of the Creative Commons Attribution (CC BY) license (https:// creativecommons.org/licenses/by/ $4.0 /)$.

\begin{abstract}
Sludge generated after washing of fruits and vegetables during agro-food processes is a complex matrix and selective methods for the identification and quantification of pesticides' residues are necessary in order to achieve a sustainable and effective management of the total sewage. The present work describes the development and validation of a reliable, simple and fast analytical method based on liquid chromatography-tandem mass spectrometry (LC-MS/MS) for the determination of 47 pesticides of different chemical classes, including organosphosphates, pyrethroids, neonicotinoids, triazoles and others, in sludge samples after QuEChERS sample preparation. The necessity of the individual steps of QuEChERS was investigated and the LC-ESI-MS/MS conditions were optimized to achieve maximum sensitivity of the target analytes. The method limits of detection (LODs) ranged between $0.0005 \mathrm{mg} / \mathrm{kg}$ (imidacloprid) and $0.05 \mathrm{mg} / \mathrm{kg}$ (beta cyfluthrin). The recoveries ranged between $71-120 \%$ and the repeatability of the method was $\leq 25 \%$ expressed as relative standard deviation. The method was applied to sludge samples generated after washing of fruits in an agro-fruit-packaging unit in Greece. The results showed the presence of 37 pesticides' active substances with concentrations ranging from low ppbs, such as fludioxinil ( $5 \mu \mathrm{g} / \mathrm{kg})$ up to low ppms such as beta cyfluthrin $(3.5 \mathrm{mg} / \mathrm{kg})$ and with their sum concentration reaching up to $19 \mathrm{mg} / \mathrm{kg}$.
\end{abstract}

Keywords: fungicides; insecticides; agricultural products; method optimization; extraction; environmentally friendly; sustainability; industrial waste

\section{Introduction}

Agro-food processes usually concern washing of fruits and vegetables before packaging and distribution to the market. The generated effluent, apart from the aqueous phase, includes sludge coming from the soil and other material from the field, such as leaves and pieces of wood that are transferred with the plastic containers. In order to achieve a sustainable and effective management of the total effluent of such a procedure it is important to be aware of the pesticides' content not only in the aqueous phase but in the sludge as well. However, sludge is a complex and difficult matrix to analyze, and suitable and reliable methods are required for the determination of contaminants present at low levels such as pesticides.

Complex matrices such as sludge usually involve labor-intensive extraction and cleanup procedures before the chromatographic analysis [1]. Soxhlet and pressurized liquid extraction (PLE) have been applied for the determination of organochlorine pesticides in sewage sludges followed by silica/aluminum oxide clean-up and GC-ion trap MS/MS 
analysis [2]. Matrix solid-phase dispersion (MSPD) has been applied for the determination of fifteen pesticides belonging to the organophosphate, triazine, organochlorine, triazole, pyrethroid, carbamate and other chemical groups in drinking water treatment sludge followed by GC-MS analysis [3]. The QuEChERS extraction (quick, easy, cheap, effective, rugged and safe) has recently been applied to limited studies regarding the determination of pesticides in sludge samples. In particular QuEChERS was applied to sewage sludge generated from agro-food industry [4], in sludge obtained from wastewater treatment plant [5] and in sludge from a pilot plant [6] in all cases followed by LC-MS/MS. Comparison between PLE and QuEChERS showed that the second was superior for samples of sediment, soil and sludge [5].

Since it was first introduced, the advantages of the QuEChERS procedure have been a strong motive for analytical scientists to transfer this "revolutionary" preparation method from fruits and vegetables to as many matrices as possible [7,8]. However, in the case of matrices where analyte-matrix interactions are stronger, the efficiency of the method had to be thoroughly investigated. In soil, stronger extraction conditions have historically been applied (pressurized liquid extraction (PLE) or soxhlet extraction, etc.), rather than just shaking, in order to overcome the strong binding characteristics of the matrix [8]. A number of applications of the QuEChERS method in soil has been published for the determination of a wide range of pesticides demonstrating the advantages of QuEChERS in terms of low cost, simplicity, short extraction time and low organic solvent consumption, offering at the same time satisfactory analytical features [9-16]. Apart from sludge [4-6] and soil [9-16] QuEChERS has been applied to other particular matrices such as cottonbased textile [17]. However, these applications mainly involve compounds prone to gas chromatography $[9-11,13,16,17]$, while the liquid chromatographic determinations include up to 25 analytes [15]. Furthermore, it is noted that since the QuEChERS extraction includes multiple steps that differentiate according to the physicochemical properties of the analytes and the matrix, all these applications include numerous modifications made by almost each user, depending on the scope of each method.

The aim of the present work was the development of a QuEChERS based sample preparation followed by LC-ESI-triple quadrupole MS/MS method after a stepwise optimization, which allows the simultaneous determination of a large number of pesticides that belong to different chemical classes in sludge at the low $\mathrm{ng} / \mathrm{g}$ level. The present work improves the coupling of QuEChERS-LC-MS/MS including pesticides with different physicochemical properties, with LogPow values between -0.24 to 7.02 and including for the first time the group of pyrethroids in the liquid chromatographic analysis of the complex matrix of sludge.

\section{Materials and Methods}

\subsection{Chemical and Reagents}

The target compounds mainly concern fungicides and insecticides, and they belong to the chemical classes of organosphosphates, pyrethroids, neonicotinoids, triazoles, benzimidazoles, pyridine compounds, pyrimidines, strobilurins, anilides, pyrazoles, diacylhydrazines, carbamates, diphenyl oxazolines, oxadiazines, pyrroles, sulfite esters and tetramic acids.

High purity (96.2-99.9\%) individual standards of the 47 selected pesticides and the internal standard triphenyl phosphate (99.5\%), were purchased from Chem Service (West Chester, PA, USA), Dr Ehrenstorfer (Augsburg, Germany), FMC (Shangai, China) and Sigma Aldrich, (Seelze, Germany). The target compounds, their molecular weight, formula, structure, function and partition coefficient (pKow) are listed in Table S1 (Supplementary Materials) $[18,19]$.

HPLC water and HPLC methanol $(\mathrm{MeOH})$ were purchased from Fischer Scientific (Leicestershire, UK) and HPLC acetonitrile (ACN) was purchased from CARLO ERBA (Val de Reuil, France). Dimethyl formamide (DMF) was obtained from Panreac Quimica (Barcelona, Spain). Individual stock standard solutions $1000 \mu \mathrm{g} / \mathrm{mL}$ of the internal standard 
and of each analyte were prepared in acetonitrile, except for chlorantraniliprole which was dissolved in methanol and carbendazim which was dissolved in ACN:DMF (1:1, v/v). The stock solutions were used for further dilutions (mix standard solutions of 100, 10 and $1 \mu \mathrm{g} / \mathrm{mL}$ ) for linearity and recovery experiments. Syringe driven Polyester (PET) filters with pore size $0.20 \mu \mathrm{m}$ and $15 \mathrm{~mm}$ diameter (Macherey-Nagel, Allentown, PA, USA) were used for the filtration of aqueous based standard and sample solutions and syringe driven Nylon filters with pore size $0.22 \mu \mathrm{m}$ and $25 \mathrm{~mm}$ diameter (Macherey-Nagel, Allentown, PA, USA) were used for the filtration of totally organic solvent standard and sample solutions before injection.

For the sample preparation $50 \mathrm{~mL}$ Falcon tubes containing $4 \mathrm{~g}$ magnesium sulfate $\left(\mathrm{MgSO}_{4}\right), 1 \mathrm{~g}$ sodium chloride $(\mathrm{NaCl}), 1 \mathrm{~g}$ sodium citrate tribasic dehydrate (Na citrate) and $0.5 \mathrm{~g}$ sodium citrate dibasic sesquihydrate ( $\mathrm{Na}$ citrate sesquihydrate) and $15 \mathrm{~mL}$ Falcon tubes containing $900 \mathrm{mg}$ magnesium sulfate $\left(\mathrm{MgSO}_{4}\right)$ and $150 \mathrm{mg}$ primary secondary amine (PSA) were purchased from Interchim (Montluçon, France). A Techne sample concentrator (Staffordshire, UK) was used for the evaporation of solvent using a gentle nitrogen stream.

\subsection{Sample Collection}

Sludge samples were collected from an agro-fruit-packaging unit in Greece in March 2019. A washing tank was used to wash fruits collected from the field. After the completion of the washing process the tank was emptied and the washing effluents were collected in a separate tank where they were stored until further treatment. Four samples from the sludge remained in different points of the washing tank, as well as one sample of the sludge of the collecting tank were sampled. The sampling was conducted with a shovel in unused plastic bags and stored at $-20^{\circ} \mathrm{C}$ until analysis.

\subsection{Sample Preparation}

After the samples were defrosted, they were homogenized manually with a spoon. The sample preparation followed was based on QuEChERS method [20] which concerns extraction with acetonitrile and clean-up by dispersive solid phase extraction in two steps. Figure 1 describes the steps of the sample preparation procedure. Ten grams of homogenized sludge were weighed directly in $50 \mathrm{~mL}$ Falcon tubes containing $4 \mathrm{~g} \mathrm{MgSO}_{4}$, $1 \mathrm{~g} \mathrm{NaCl}, 1 \mathrm{~g} \mathrm{Na}$ citrate and $0.5 \mathrm{~g} \mathrm{Na}$ citrate sesquihydrate and spiked with $100 \mu \mathrm{L}$ of $8 \mu \mathrm{g} / \mathrm{mL}$ of the internal standard triphenyl-phosphate. For the recovery study and the method validation, the samples were additionally spiked with the appropriate aliquot of 1 or $10 \mu \mathrm{g} / \mathrm{mL}$ mix standard solution. Next, $10 \mathrm{~mL}$ ACN were added and immediately the Falcon tube was vortexed for $1 \mathrm{~min}$ and centrifuged for $5 \mathrm{~min}$ at $3000 \mathrm{rpm}$ (revolutions per minute). Two $\mathrm{mL}$ of the supernatant were filtered with $0.22 \mu \mathrm{m}$ Nylon syringe filters and measured by LC-MS/MS. This fraction of the sample was named Fraction A, and was evaluated during method development. Six $\mathrm{mL}$ of the same supernatant were transferred to the $15 \mathrm{~mL}$ Falcon tube containing $900 \mathrm{mg} \mathrm{MgSO}_{4}$ and $150 \mathrm{mg}$ PSA for the second extraction step. The tube was vortexed for $1 \mathrm{~min}$ and centrifuged for $5 \mathrm{~min}$ at $3000 \mathrm{rpm}$. Two $\mathrm{mL}$ of the supernatant were filtered with $0.22 \mu \mathrm{m}$ Nylon syringe filters syringe filters and measured by LC-MS/MS (Fraction B). Three $\mathrm{mL}$ of the same supernatant were transferred to a glass test tube and evaporated to dryness under a constant stream of nitrogen at $40{ }^{\circ} \mathrm{C}$, finally the extract was reconstituted in $1.5 \mathrm{~mL}$ of $\mathrm{MeOH} / \mathrm{H}_{2} \mathrm{O}(1 / 1, v / v)$ followed by one-minute vortex stirring (Fraction $\mathrm{C}$ ) and filtered with $0.20 \mu \mathrm{m}$ PET syringe filter before LC-MS/MS measurement. In every batch of six sludge samples a procedural blank was also prepared according to the same procedure followed for the samples but weighing $10 \mathrm{~g}$ of water instead of sludge sample. All the target analytes were determined and quantified in the three collected Fractions (A, B and C) of spiked sludge samples. Qualitative and quantitative evaluation of the results obtained from the three fractions was performed for the final selection of the method protocol. 
- Ten $\mathrm{g}$ of homogenised sludge in $50 \mathrm{~mL}$ Falcon tubes containing $4 \mathrm{~g} \mathrm{MgSO}_{4}, 1 \mathrm{~g} \mathrm{NaCl}, 1 \mathrm{~g} \mathrm{Na}$ citrate and $0.5 \mathrm{~g}$ Na citrate sesquihydrate

- Spiking with 80 ng/g Triphenyl-Phosphate (I.S)

- Addition of $10 \mathrm{~mL} \mathrm{ACN}$

- Vortex (1min)

- Centrifugation (5 min, $3000 \mathrm{rpm})$

- Transfer of $6 \mathrm{~mL}$ of supernatant to $15 \mathrm{~mL}$ Falcon tube containing $900 \mathrm{mg} \mathrm{MgSO}_{4}$ and $150 \mathrm{mg}$ PSA

- Vortex (1min)

- Centrifugation (5 min, $3000 \mathrm{rpm})$
- Filtration of $2 \mathrm{~mL}$ of supernatant $(0.22 \mu \mathrm{m}$ Nylon syringe filters) Fraction A

- LC-MS/MS measurement

Step applied during method development - not included in final protocol
- Transfer of $3 \mathrm{~mL}$ of supernatant to glass test tube

- Evaporation to dryness under constant stream of nitrogen at $40^{\circ} \mathrm{C}$.

- Reconstitution in $1.5 \mathrm{~mL}$ of $\mathrm{MeOH} / \mathrm{H}_{2} \mathrm{O}(1 / 1, v / v)$.

- Vortex (1 min)

- Filtration with $0.20 \mu \mathrm{m}$ PET syringe filter Fraction C

- LC-MS/MS measurement
- Filtration of $2 \mathrm{~mL}$ of supernatant $(0.22$ $\mu \mathrm{m}$ Nylon syringe filters) Fraction B - LC-MS/MS measurement

Figure 1. Method protocol.

The determination of moisture of sludge samples was performed by weighing accurately an amount of sample of approximately $4-5 \mathrm{~g}$ and drying in an oven at $100{ }^{\circ} \mathrm{C}$ until stable weight.

\subsection{LC-MS/MS Measurements}

\subsubsection{LC-MS/MS Optimization}

The LC-MS/MS measurements were carried out using a Varian 1200L Prostar LC/MS triple quadrupole with an electrospray ionization interface (ESI) in positive and negative polarity (Walnut Creek, California, USA). Varian MS Workstation software version 6.8 was used for the data recording and analysis including peak integration. Chromatographic separation was performed with a Kinetex C18 analytical column $(50 \times 2.10 \mathrm{~mm})$ with particle size $2.6 \mu \mathrm{m}$ and pore diameter $100 \AA$, equipped with a guard C18 column $(2 \times 2.10 \mathrm{~mm})$.

The optimization of the LC-MS/MS conditions was based on the strategy plan proposed in previous work [21].

The first step was the selection of the parent mass / masses and their capillary voltage and the selection of the product ions and their collision energies (4 SRMs selected for each compound). In particular, stock standard solutions of each compound diluted in methanol (1-5 $\mu \mathrm{g} / \mathrm{mL}$ ) were measured by flow injection analysis (FIA) at $50 \mu \mathrm{L} / \mathrm{min}$ flow rate for the selection of the ionization polarity, the parent masses, the optimization of the capillary voltages, the selection of the product ions and the optimization of the collision energies. Full scan mode (MW $\pm 100 \mathrm{amu}$ ) was applied for the selection of the ionization polarity and parent masses, which was based on the highest abundance. After the selection of the ionization polarity and parent mass, the capillary voltage that enhances its ionization was optimized and the breakdown curve was generated. Four selected reaction monitoring transitions (SRM) were selected for each compound and their collision energies were optimized. Based on these results the two transitions with the highest sensitivity were selected for each compound for the LC-MS/MS method as quantification (SRM1) and confirmation (SRM2) transitions.

Next, the analytes were grouped in eight mixed solutions of five to eight compounds, based on their structure and polarity, in order to investigate their chromatographic be- 
havior and complete the optimization of the LC-MS/MS parameters. The mixed solutions were injected separately to the analytical column and four SRMs were recorded for each compound.

The starting point of the gradient elution was based on the European Standard EN 15662 [20], but since the analytes exhibited very different chromatographic behavior further optimization of the gradient was required in order to have good chromatography in terms of sensitivity (signal to noise ratio), resolution and analysis time. It is noted that the scope of the gradient was to spread the eluted chromatographic peaks throughout the analysis time so that all segments of the MS/MS method to include the least possible compounds, so that the data points to be adequate ( $>10$ points) for quantification. Based on these experiments and on the retention time of the analytes, twenty time-segments of one minute were created for the MS/MS method and each SRM was recorded only for three consecutive time segments (three minutes) based on the retention time of the target compound. The appropriate dwell and scan time was selected for each segment based on the number of monitored transitions so that adequate number of data points were recorded for each chromatographic peak.

After the selection of the optimum gradient, it was considered appropriate to optimize the drying gas temperature. In particular, because of the fact that the gradient starts with high content of aqueous mobile phase, $90 \%$, which decreases to low content of $10 \%$ until the elution of the last peaks, optimization experiments were conducted for the drying gas temperature examining a wide range of temperatures with highest value $340{ }^{\circ} \mathrm{C}$, lowest value $200^{\circ} \mathrm{C}$, and intermediate value $280{ }^{\circ} \mathrm{C}$, while a ramp program starting at $340{ }^{\circ} \mathrm{C}$, remaining stable for the first three minutes and decreased to $200^{\circ} \mathrm{C}$ until the 16 th min in steps of $10^{\circ} \mathrm{C}$ was also tested.

\subsubsection{LC-MS/MS Final Conditions}

The optimum gradient elution applied consisted of a mobile phase composed of $5 \mathrm{mM}$ ammonium formate and $0.1 \% v / v$ formic acid in methanol (solvent $\mathrm{A}$ ) and $5 \mathrm{mM}$ ammonium formate and $0.1 \% v / v$ formic acid in water (solvent $\mathrm{B}$ ) at $0.25 \mathrm{~mL} / \mathrm{min}$ flow rate. The gradient starts at A/B 90/10, remains for $0.5 \mathrm{~min}$ and changes linearly to A/B 10/90 in $11.5 \mathrm{~min}$ where it remains stable until the 20th minute. Afterwards the composition of the gradient returns to the initial ratio A/B 90/10 and remains stable for $10 \mathrm{~min}$ for equilibration. The column oven was set at $40^{\circ} \mathrm{C}$ and the injection volume at $5 \mu \mathrm{L}$.

Electrospray (ESI) in positive polarity was applied for the 46 pesticides and ESI in negative polarity for Fludioxonil. Data were acquired in SRM mode with two transitions per analyte and one transition for the internal standard. Table 1 presents the SRMs of the target compounds and the internal standard, ordered by their retention time, along with the capillary voltage (CV) and collision energy (CE) of each transition. The acquiring MS/MS method was divided in twenty (20) time-segments of one minute, except for the last segment (10 $\mathrm{min}$ ) and the SRMs of each analyte were recorded only for three consecutive time-segments based on the retention time of the analyte. The drying gas temperature was set at $340{ }^{\circ} \mathrm{C}$ for the first three minutes and decreased to $200{ }^{\circ} \mathrm{C}$ until the 16 th min in steps of $10^{\circ} \mathrm{C}$. The number of SRMs included in each time-segment, the dwell time of each transition, the total scan time of each time-segment and the drying gas temperature set for each time-segment are presented in Table S2 (Supplementary Materials). The drying gas pressure $\left(\mathrm{N}_{2}\right)$ was set at $19 \mathrm{psi}$ and the nebulizing gas pressure at $55 \mathrm{psi}$. The needle voltage was held at $5 \mathrm{kV}$. All the working LC-MS/MS conditions are the same for the positive and the negative polarity. 
Table 1. Selected reaction monitoring (SRM) transitions of the target compounds ordered by retention time (RT). Capillary voltage (CV) and collision energy (CE) for the SRM1 and SRM2.

\begin{tabular}{|c|c|c|c|c|}
\hline Analytes & $\begin{array}{c}\mathrm{RT} \\
(\mathrm{min})\end{array}$ & $\begin{array}{c}\text { SRM1/SRM2 } \\
(\mathrm{m} / \mathrm{z})\end{array}$ & $\begin{array}{c}\text { CV (V) } \\
\text { SRM1/SRM2 }\end{array}$ & $\begin{array}{c}\text { CE (eV) } \\
\text { SRM1/SRM2 }\end{array}$ \\
\hline Flonicamid & 3.1 & $230>203 / 230>148$ & $52 / 52$ & $14 / 20.5$ \\
\hline Carbendazim & 3.6 & $192>160 / 192>132$ & $48 / 48$ & $13 / 27$ \\
\hline Thiamethoxam & 3.6 & $292>211 / 294>211$ & $30 / 30$ & $8.5 / 20$ \\
\hline Thiabendazole & 4.4 & $202>175 / 202>131$ & $76 / 76$ & $19.5 / 28$ \\
\hline Clothianidin & 4.6 & $250>169 / 250>132$ & $30 / 30$ & $9.5 / 11.5$ \\
\hline Imidacloprid & 4.6 & $256>209 / 256>175$ & $40 / 40$ & $11.5 / 14$ \\
\hline Acetamiprid & 5.1 & $223>126 / 225>128$ & $56 / 56$ & $17 / 17$ \\
\hline Thiacloprid & 6.0 & $253>127 / 255>128$ & $48 / 52$ & $18 / 17.5$ \\
\hline Thiophanate Methyl & 7.8 & $343>151 / 343>311$ & $36 / 36$ & $14.5 / 7.5$ \\
\hline Imazalil & 9.3 & $297>159 / 297>201$ & $60 / 60$ & $18 / 13.5$ \\
\hline Pyrimethanil & 9.9 & $200>107 / 200>82$ & $70 / 70$ & $21 / 22$ \\
\hline Chlorantraniliprole & 10.3 & $484>286 / 484>453$ & $36 / 36$ & $8.5 / 14$ \\
\hline Phosmet & 10.4 & $318>160 / 318>133$ & $36 / 36$ & $8.5 / 32$ \\
\hline Boscalid & 10.9 & $343>307 / 343>309$ & $64 / 64$ & $13.5 / 14$ \\
\hline Cyproconazole & 11.2 & $292>70 / 292>125$ & $48 / 48$ & $13.5 / 26$ \\
\hline Fluxapyroxad & 11.2 & $382>362 / 382>342$ & $48 / 48$ & $9.5 / 17$ \\
\hline Myclobutanil & 11.2 & $289>70 / 289>124.9$ & $52 / 52$ & $12.5 / 28$ \\
\hline Methoxyfenozide & 11.3 & $369>149 / 369>313$ & $30 / 30$ & $13 / 5.5$ \\
\hline Bupirimate & 11.5 & $317>166 / 317>108$ & $64 / 64$ & $20.5 / 23$ \\
\hline Cyprodinil & 11.5 & $226>93 / 226>107.9$ & $76 / 76$ & $30 / 22$ \\
\hline Fluquinconazole & 11.5 & $376>307 / 376>349$ & $56 / 56$ & $23.5 / 14$ \\
\hline Azinphos Ethyl & 11.6 & $346>132 / 346>160$ & $30 / 30$ & $12.5 / 6$ \\
\hline Fluopyram & 11.6 & $397>173 / 397>208$ & $60 / 60$ & $24 / 16.5$ \\
\hline Spirotetramat & 11.6 & $374>216 / 374>302$ & $60 / 60$ & $26.5 / 12$ \\
\hline Fenbuconazole & 11.8 & $337>125 / 337>70$ & $64 / 64$ & $24.5 / 14$ \\
\hline Fenoxycarb & 12.0 & $302>116 / 302>88$ & $32 / 32$ & $7.5 / 15$ \\
\hline Kresoxim Methyl & 12.1 & $314>116 / 314>206$ & $30 / 30$ & $9.5 / 5$ \\
\hline Tebufenozide & 12.1 & $353>133 / 353>297$ & $30 / 30$ & $14.5 / 5.5$ \\
\hline Tebuconazole & 12.1 & $308>70 / 310>70$ & $56 / 60$ & $14.5 / 14$ \\
\hline $\begin{array}{l}\text { Triphenyl-Phosphate } \\
\text { (I.S) }\end{array}$ & 12.4 & $327>152$ & 88 & 29 \\
\hline Phosalone & 12.5 & $368>182 / 368>111$ & $48 / 48$ & $10.5 / 32.5$ \\
\hline Pyraclostrobin & 12.5 & $388>164 / 388>194$ & $36 / 36$ & $13.5 / 8.5$ \\
\hline Chlorpyrifos-Methyl & 12.6 & $322>125 / 322>290$ & $44 / 44$ & $15.5 / 10.5$ \\
\hline Difenoconazole & 12.7 & $406>251 / 406>337$ & $68 / 68$ & $20 / 12$ \\
\hline Trifloxystrobin & 13.0 & $409>186 / 409>145$ & $40 / 40$ & $12 / 39.5$ \\
\hline Indoxacarb & 13.0 & $528>249 / 528>150$ & $48 / 48$ & $11.5 / 20$ \\
\hline Pyriproxyfen & 13.6 & $322>96 / 322>185$ & $40 / 40$ & $11.5 / 19.5$ \\
\hline Chlorpyrifos & 13.7 & $352>200 / 350>198$ & $36 / 40$ & $13.5 / 13.5$ \\
\hline Etoxazole & 14.1 & $360>141 / 360>113$ & $60 / 60$ & $27 / 45$ \\
\hline Propargite & 14.1 & $368>231 / 368>175$ & $30 / 30$ & $7 / 12$ \\
\hline Beta Cyfluthrin & 14.5 & $451>191 / 451>193$ & $32 / 32$ & $11.5 / 11.5$ \\
\hline Fenpyroximate & 14.5 & $422>135 / 422>107$ & $56 / 56$ & $28 / 40.5$ \\
\hline Lambda Cyhalothrin & 14.7 & $467>466 / 467>225$ & $36 / 36$ & $5 / 13.5$ \\
\hline Deltamethrin & 14.9 & $524>281 / 524>282$ & $36 / 36$ & $14 / 13.5$ \\
\hline Fluvalinate & 15.6 & $503>180 / 503>208$ & $36 / 36$ & $24.5 / 8.5$ \\
\hline Etofenprox & 16.1 & $394>177 / 394>135$ & $30 / 30$ & $10 / 20.5$ \\
\hline Bifenthrin & 16.7 & $440>181 / 440>182$ & $30 / 30$ & $10.5 / 10$ \\
\hline Fludioxonil $^{1}$ & 11.0 & $247>180 / 247>169$ & $68 / 68$ & $27.5 / 34.5$ \\
\hline
\end{tabular}

${ }^{1}$ Fludioxonil was monitored in the negative (-) ESI mode. 


\subsection{Method Validation}

The linearity of the response of the LC-ESI-MS/MS system versus analyte concentrations was examined with standard calibration curves prepared in acetonitrile for the quantification of the analytes contained in Fractions A and B and in methanol/water (1/1, $v / v)$ for the quantification of the analytes contained in Fraction C. Five standard solutions were measured with concentration levels ranging between 1 and $500 \mathrm{ng} / \mathrm{mL}$ for all the analytes. The working solutions in ACN and methanol/water $(1 / 1, v / v)$ contained also 100 and $200 \mathrm{ng} / \mathrm{mL}$ of triphenyl phosphate as internal standard, respectively.

Matrix matched calibration curves were prepared with sludge samples spiked with the target analytes at four levels between 1-200 ng/g and with triphenyl phosphate at $100 \mathrm{ng} / \mathrm{g}$. Spiked samples and non-spiked samples of the same sampling point were analyzed according to the protocol described in Section 2.3 "Sample preparation". The final linear equation of the matrix matched calibration curve resulted after the subtraction of the signal of the unfortified sample from the signal of the fortified samples.

For the assessment of the overall precision and accuracy, the method was applied to sludge sample that was spiked with the target analytes at four fortification levels $(1,10$, 50 and $200 \mathrm{ng} / \mathrm{g}$ ) and analyzed in five replicates. The recovery (\%R) of the method was calculated by subtracting the concentration measured in the non-spiked sample from that measured in the spiked sample and then dividing with the spiked concentration $\left(\mathrm{C}_{\mathrm{ADDED}}\right)$ according to Equation (1).

$$
\% \mathrm{R}=\frac{\mathrm{C}_{\text {SPIKEDSAMPLE }}-\mathrm{C}_{\text {NONSPIKEDSAMPLE }}}{\mathrm{C}_{\mathrm{ADDED}}} \times 100
$$

The method limit of detection (LOD) for the different analytes was defined as the concentration of the analyte in matrix that was equal to three times the average level of the baseline noise close to the peak. The method limit of quantification (LOQ) was defined as the lowest validated concentration with acceptable recovery and repeatability. The acceptability criteria were based on the guidance document SANTE/2020/12830, Rev.1 [22] which reports a general requirement for the mean recovery to be in the range of $70-120 \%$ and the precision to be $\leq 20 \%$ expressed as relative standard deviation (RSD), independently the sample matrix and the concentration level. However, it is noted that for difficult matrices such as food of plant and animal origin the acceptability criteria for precision at low concentration levels $\leq 10 \mathrm{ng} / \mathrm{g}$ extends to $30 \%$ in the same guidance document. Sludge is considered a difficult matrix and the same acceptability criteria could be adopted.

\section{Results and Discussion}

\subsection{Optimization of LC-ESI-MS/MS}

The optimization of the drying gas temperature during electrospray ionization proved to be a critical parameter. Figure 2 illustrates the peak area of the chromatographic peak of three indicative analytes (carbendazim — early eluting, methoxyfenozide-intermediate eluting, etofenprox-late eluting) obtained at three temperatures of drying gas, where different patterns are observed for the different analytes. It is shown that for the early eluting carbendazim with Retention Time (RT) at $3.6 \mathrm{~min}$, the higher the drying gas temperature the higher the signal of the peak area, whereas for methoxyfenozide which elutes in the middle of the chromatographic run (RT: $11.4 \mathrm{~min}$ ) and etofenprox which is one of the last eluting compounds (RT: $16.1 \mathrm{~min}$ ) lower temperature for the drying gas is required. The change of the sensitivity in relation to the drying gas temperature follows the gradient of the mobile phase as regards the content of water. The higher the content of water in the mobile phase the higher temperature is required for the solvent to evaporate during the electrospray ionization. Based on these data a gradient program of drying gas was applied in order to achieve optimum sensitivity of all analytes (Table S2 in Supplementary Materials). 


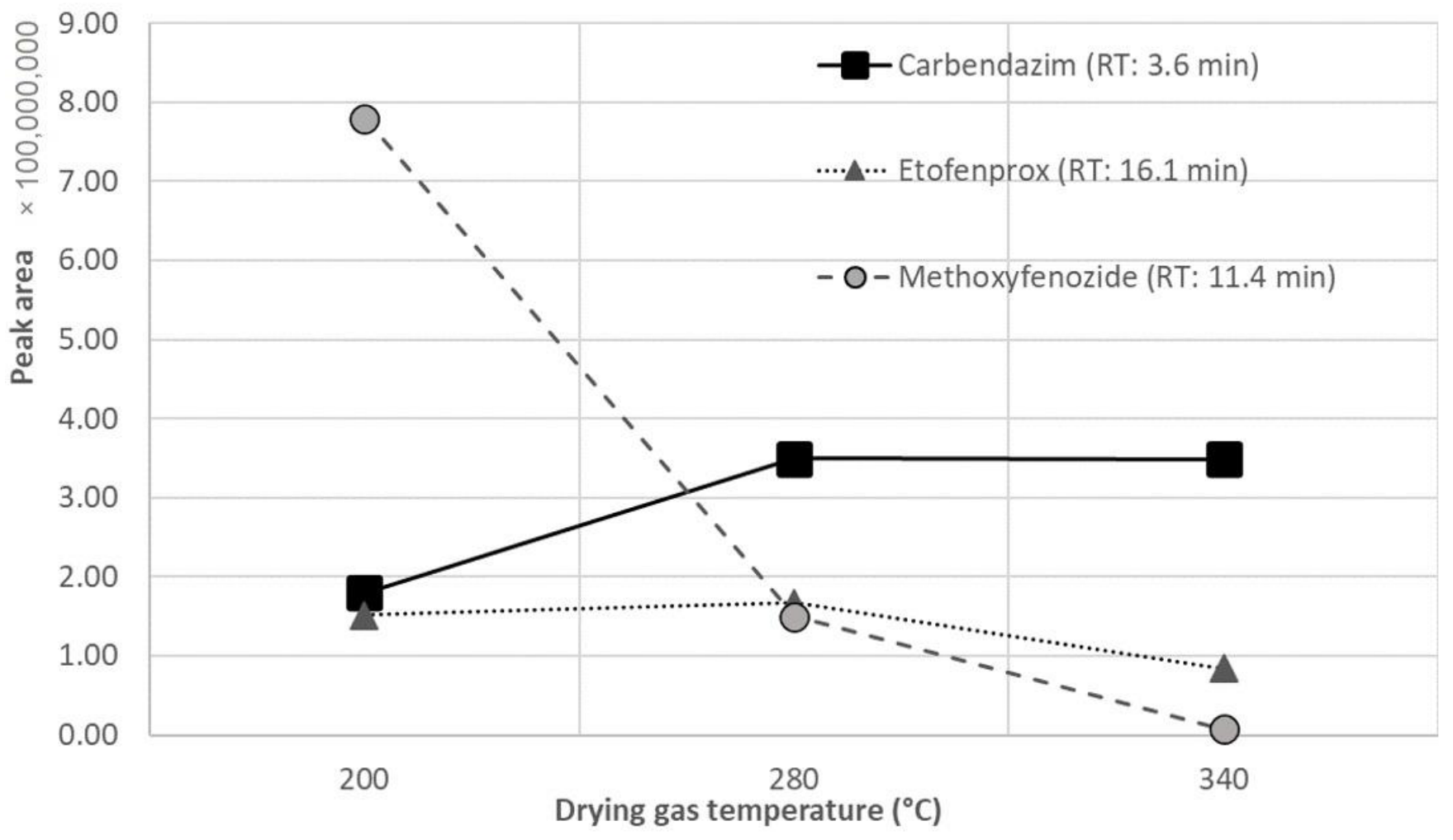

Figure 2. Effect of drying gas temperature in ESI on the sensitivity (as peak area) of three different analytes (carbendazim, methoxyfenozide and etofenprox). RT: retention time $\times$.

\subsection{Optimization of the Sample Preparation}

The final method protocol is illustrated in Figure 1. Qualitative evaluation of chromatograms obtained from the three different Fractions A, B and C from the sample preparation revealed that in Fractions $A$ and $B$ the signal of the early eluting analytes (with RT $<8$ min) was significantly lower than the corresponding signal of Fraction C. At the same time the signal of the late eluting analytes (with RT $>15 \mathrm{~min}$ ) was significantly lower in Fraction C comparing to the signal obtained from Fractions A and B. This comparison is illustrated in Figure 3 with the Total Ion Chromatograms of Fraction A, B and C of the same fortified sludge sample at $10 \mathrm{ng} / \mathrm{g}$. This can be attributed to the fact that the analytes in Fraction $\mathrm{C}$ are dissolved in $\mathrm{MeOH} /$ water $(1 / 1, v / v)$ whereas the analytes in Fractions $\mathrm{A}$ and $\mathrm{B}$ are dissolved in acetonitrile. The results show that for compounds with low partition coefficient $(\log P o w<1.5)$, which concern the early eluting analytes flonicamid, carbendazim, thiamethoxam, thiabendazole, clothianidin, imidacloprid, acetamiprid, thiacloprid and thiophanate methyl the solvent the most appropriate is $\mathrm{MeOH} /$ water $(1 / 1$, $v / v)$. On the other hand, for analytes with high partition coefficient $(\log P o w>4.5)$ the organic solvent acetonitrile significantly improves the chromatography and potentially the dissolvation and ionization during the electrospray. For analytes with intermediate values of partition coefficient $(1.5<\log$ Pow $<4.5)$ the signals obtained from Fractions B and $C$ were comparable. Overlapping comparison of TIC chromatograms of Fraction B (green line) and of Fraction C (orange line) of a sludge sample fortified with all the analytes at $10 \mathrm{ng} / \mathrm{g}$ and internal standard at $100 \mathrm{ng} / \mathrm{g}$ is presented in Figure 4. It is noted that all the chromatographic peaks of fractions $\mathrm{A}, \mathrm{B}$ and $\mathrm{C}$ were identified by reference standard solutions prepared in acetonitrile (A, B) and in methanol/water (C), accordingly. It was demonstrated by the reference standard solutions that the solvent did not affect the elution sequence of the analytes but slightly their absolute retention time. 


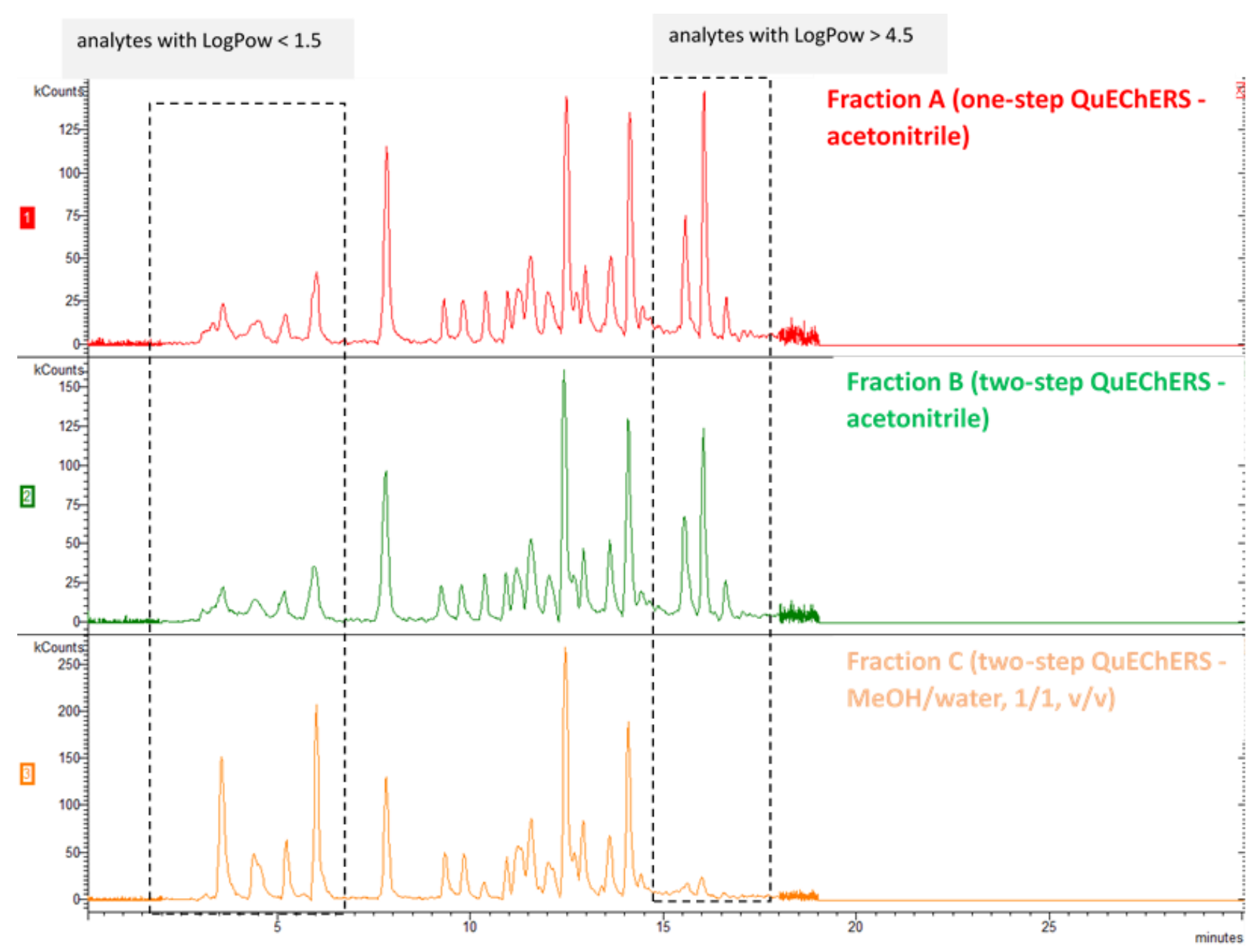

Figure 3. Comparison of TIC chromatograms of Fraction A (red line), Fraction B (green line) and Fraction C (orange line) of a sludge sample fortified with all the analytes at $10 \mathrm{ng} / \mathrm{g}$ and internal standard at $100 \mathrm{ng} / \mathrm{g}$.

Regarding the comparison between Fraction A and B it was observed that for most analytes eluted at the end of the chromatogram the matrix effect in Fraction A was higher ranging between $28-41 \%$, than the matrix effect observed in Fraction $B$ which ranged between $1-7 \%$. The matrix effect (ME\%) was estimated from fortified samples at $10 \mathrm{ng} / \mathrm{g}$ according to the following equation $\mathrm{ME} \%=100-\mathrm{Rec} \%$. Indicative values are presented in Table S3 (Supplementary Materials). The lower matrix effect of Fraction B can be attributed to the fact that the analytes in this Fraction have been subjected to one additional purification step with PSA comparing to Fraction A (Figure 1) and therefore the extracts of Fraction B contain less matrix components.

It is noted that the common analytes determined in the present work with those determined in the relevant study of agro-food industry sludge from Spain [4] are five out of ten (acetamiprid, carbendazim, imidacloprid, myclobutanil and thiabendazole). There are eight common analytes (azinphos-ethyl, carbendazim, chlorpyrifos, imazalil, imidacloprid, pyriproxyfen, tebuconazole and thiabendazole) out of fifty with the study on the sludge obtained from wastewater treatment plant [5] and four common neonicotinoids pesticides (imidacloprid, clothianidin, thiacloprid and thiamethoxam) out of twelve several analytes of the study in sludge from a pilot plant [6]. It is also highlighted that the sample preparation followed in the present study differs from the others in the material used for the second step of the cleanup with dispersive solid phase extraction which consisted of $\mathrm{MgSO}_{4}$ and PSA, while the other studies used other combinations such as $\mathrm{MgSO}_{4}+\mathrm{PSA}+\mathrm{C} 18[4,5]$ or PSA or C18 or PSA + C18 [6]. In addition, the present method 
considers two fractions $(\mathrm{B}+\mathrm{C})$ of the same cleaned-up sample with different solvents, $\mathrm{ACN}$ and $\mathrm{MeOH} / \mathrm{H}_{2} \mathrm{O}(1 / 1, v / v)$ filtered with different materials, Nylon and PET, respectively before LC injection. Thus, it is revealed that suitable modifications are necessary based on the target analytes of each method.

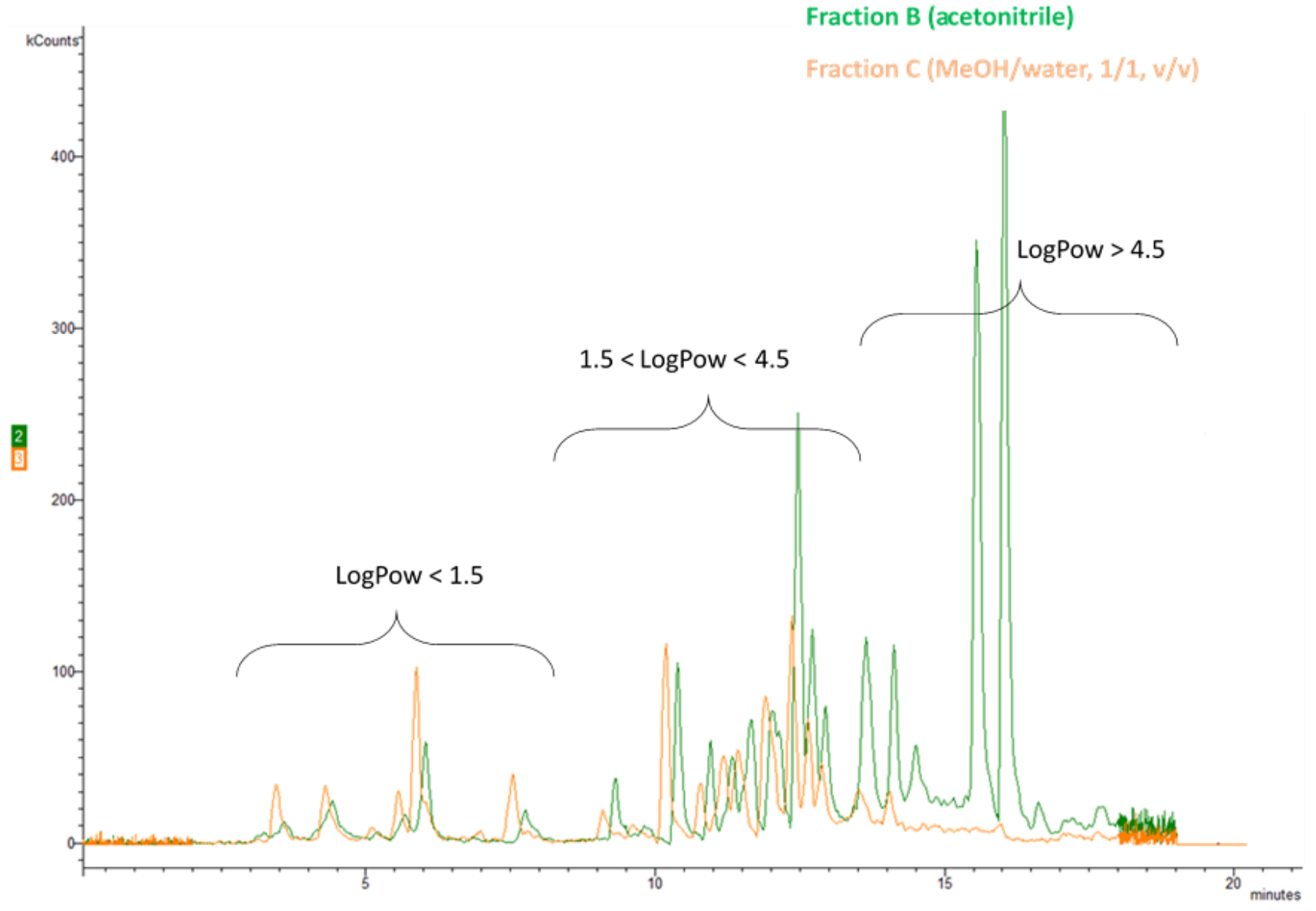

Figure 4. Comparison of TIC chromatograms of Fraction B (green line) and of Fraction C (orange line) of a sludge sample fortified with all the analytes at $10 \mathrm{ng} / \mathrm{g}$ and internal standard at $100 \mathrm{ng} / \mathrm{g}$.

\subsection{Method Performance}

The SRM chromatograms used for the quantification and identification, SRM1 and SRM2, respectively, of the analytes determined in Fraction C of sludge sample fortified at $10 \mathrm{ng} / \mathrm{g}$, are presented in Figure S1i-vii (Supplementary Materials). The corresponding SRM chromatograms of the analytes determined in Fraction B are presented in Figure S2i-v (Supplementary Materials).

The method performance parameters in terms of limit of detection (LOD), limit of quantification (LOQ), recovery and precision expressed as relative standard deviation (\%RSD) at the LOQ, as well as the linear concentration range and the correlation coefficient of the calibration lines are presented in Table 2. The linear regression equations $\mathrm{y}=\mathrm{a} \times \mathrm{C}+\mathrm{b}$ along with the $p$-values of the slope (a) and the intercept (b) are presented in Table S4 (Supplementary Materials). 
Table 2. Method performance parameters in sludge.

\begin{tabular}{|c|c|c|c|c|c|c|c|}
\hline Compound. & $\begin{array}{l}\text { LOD } \\
\text { (ng/g) }\end{array}$ & $\begin{array}{c}\text { LOQ } \\
\text { (ng/g) }\end{array}$ & $\begin{array}{c}\% \mathrm{R} \\
(\mathrm{LOQ}, n=5)\end{array}$ & $\begin{array}{c}\% \text { RSD } \\
(\mathrm{LOQ}, n=5)\end{array}$ & $\begin{array}{c}\text { Linear Range } \\
\text { ng/g }\end{array}$ & $\mathbf{r}^{2}$ & FRACTION \\
\hline Acetamiprid & 0.5 & 1 & 100 & 14 & $1-200$ & 0.9903 & C \\
\hline Bupirimate & 0.5 & 1 & 108 & 16 & $1-200$ & 0.9945 & C \\
\hline Carbendazim & 0.5 & 1 & 91 & 21 & $1-200$ & 0.9939 & $\mathrm{C}$ \\
\hline Clothianidin & 0.5 & 1 & 107 & 16 & $1-200$ & 0.9986 & C \\
\hline Fluopyram & 0.5 & 1 & 77 & 25 & $1-200$ & 0.9912 & $\mathrm{C}$ \\
\hline Imidacloprid & 0.5 & 1 & 109 & 24 & $1-200$ & 0.9909 & C \\
\hline Thiacloprid & 0.5 & 1 & 112 & 18 & $1-200$ & 0.9934 & C \\
\hline Boscalid & 5 & 10 & 84 & 18 & $10-200$ & 0.9902 & C \\
\hline Chlorantraniliprole & 5 & 10 & 71 & 19 & $10-200$ & 0.9944 & C \\
\hline Cyproconazole & 5 & 10 & 91 & 15 & $10-200$ & 0.9926 & $\mathrm{C}$ \\
\hline Cyprodinil & 5 & 10 & 84 & 17 & $10-200$ & 0.9913 & C \\
\hline Difenoconazole & 5 & 10 & 112 & 20 & $10-200$ & 0.9913 & C \\
\hline Fenbuconazole & 5 & 10 & 84 & 9 & $10-200$ & 0.9923 & $\mathrm{C}$ \\
\hline Fenoxycarb & 5 & 10 & 87 & 8 & $10-200$ & 0.9923 & C \\
\hline Flonicamid & 5 & 10 & 76 & 16 & $10-200$ & 0.9904 & $\mathrm{C}$ \\
\hline Fludioxonil & 5 & 10 & 89 & 10 & $10-200$ & 0.9939 & C \\
\hline Fluquinconazole & 5 & 10 & 71 & 8 & $10-200$ & 0.9921 & C \\
\hline Fluxapyroxad & 5 & 10 & 104 & 20 & $10-200$ & 0.9909 & C \\
\hline Kresoxim Methyl & 5 & 10 & 84 & 20 & $10-200$ & 0.9992 & C \\
\hline Methoxyfenozide & 5 & 10 & 110 & 15 & $10-200$ & 0.9941 & C \\
\hline Myclobutanil & 5 & 10 & 88 & 19 & $10-200$ & 0.9948 & C \\
\hline Tebufenozide & 5 & 10 & 88 & 6 & $10-200$ & 0.9989 & $\mathrm{C}$ \\
\hline Tebuconazole & 5 & 10 & 84 & 19 & $10-200$ & 0.9956 & $\mathrm{C}$ \\
\hline Thiabendazole & 5 & 10 & 96 & 10 & $10-200$ & 0.9994 & C \\
\hline Thiamethoxam & 5 & 10 & 90 & 14 & $10-200$ & 0.9925 & C \\
\hline Thiophanate Methyl & 5 & 10 & 82 & 15 & $10-200$ & 0.9953 & C \\
\hline Bifenthrin & 5 & 10 & 98 & 11 & $10-200$ & 0.9933 & $\mathrm{~B}$ \\
\hline Deltamethrin & 5 & 10 & 98 & 22 & $10-200$ & 0.9913 & B \\
\hline Etofenprox & 5 & 10 & 96 & 6 & $10-200$ & 0.9967 & B \\
\hline Etoxazole & 5 & 10 & 103 & 13 & $10-200$ & 0.9916 & B \\
\hline Fenpyroximate & 5 & 10 & 94 & 17 & $10-200$ & 0.9922 & $\mathrm{~B}$ \\
\hline Imazalil & 5 & 10 & 108 & 10 & $10-200$ & 0.9938 & B \\
\hline Indoxacarb & 5 & 10 & 85 & 24 & $10-200$ & 0.9950 & B \\
\hline Phosalone & 5 & 10 & 101 & 15 & $10-200$ & 0.9946 & $\mathrm{~B}$ \\
\hline Phosmet & 5 & 10 & 108 & 18 & $10-200$ & 0.9910 & B \\
\hline Propargite & 5 & 10 & 98 & 6 & $10-200$ & 0.9913 & B \\
\hline Pyraclostrobin & 5 & 10 & 107 & 13 & $10-200$ & 0.9961 & B \\
\hline Pyrimethanil & 5 & 10 & 104 & 14 & $10-200$ & 0.9923 & $\mathrm{~B}$ \\
\hline Pyriproxyfen & 5 & 10 & 90 & 19 & $10-200$ & 0.9935 & B \\
\hline Spirotetramat & 5 & 10 & 75 & 7 & $10-200$ & 0.9918 & B \\
\hline Trifloxystrobin & 5 & 10 & 111 & 18 & $10-200$ & 0.9911 & B \\
\hline Azinphos Ethyl & 10 & 50 & 91 & 15 & $10-200$ & 0.9963 & C \\
\hline Lambda Cyhalothrin & 10 & 50 & 117 & 14 & $50-200$ & 0.9831 & B \\
\hline Chlorpyrifos Methyl & 25 & 50 & 90 & 20 & $50-200$ & 0.9937 & B \\
\hline Chlorpyrifos & 25 & 50 & 99 & 21 & $50-200$ & 0.9862 & B \\
\hline Tau Fluvalinate & 25 & 50 & 101 & 20 & $50-200$ & 0.9960 & B \\
\hline Beta Cyfluthrin & 50 & 100 & 73 & 25 & $50-200$ & 0.9891 & $\mathrm{~B}$ \\
\hline
\end{tabular}

The method LODs ranged between $0.5-5 \mathrm{ng} / \mathrm{g}$ for most of the target analytes (41 out of 47), with the majority of the neonicotinoids, the benzimidazole carbendazim, the pyrimidine bupirimate and the pyridine fluopyram to exhibit the highest sensitivity $(0.5 \mathrm{ng} / \mathrm{g})$. On the other hand, the organophosphates azinphos ethyl, chlorpyrifos and chlorpyrifos methyl and the pyrethroids lambda cyhalothrin, tau fluvalinate and beta cyfluthrin showed lower sensitivity with LODs between 10-50 ng/g. Accordingly, the method LOQs ranged between 1-10 ng/g for the majority of the target analytes. The LOQ for azinphos ethyl, chlorpyrifos, chlorpyrifos methyl, lambda cyhalothrin and tau fluvalinate was $50 \mathrm{ng} / \mathrm{g}$ 
and for beta cyfluthrin the LOQ was $100 \mathrm{ng} / \mathrm{g}$. It is noteworthy that there is no legislative limit for the monitoring of pesticides in sludge or in soil, however a general data requirement for the limit of quantification in soil in the framework of the European pesticides' approval is $50 \mathrm{ng} / \mathrm{g}$ [22]. The developed method meets this data requirement, except for the case of beta cyfluthrin. In addition, the correlation coefficient of the matrix matched calibration lines is higher than 0.99 , for all analytes except for lambda cyhalothrin, beta cyfluthrin and chlorpyrifos. This can be attributed to the increased matrix effect for these substances observed for the sludge samples. The correlation coefficient of the calibration lines prepared in solvent was higher than 0.99 in all cases. The recoveries were in the range of $71-120 \%$ and the $\%$ RSD was $\leq 25 \%$ for all analytes at the low fortification levels of 1 and $10 \mathrm{ng} / \mathrm{g}$ (acceptability criteria $30 \%$ ) and $\leq 20 \%$ for all the analytes, at fortification levels of 50, 100 and $200 \mathrm{ng} / \mathrm{g}$, except for beta cyfluthrin for which the \%RSD was $25 \%$ at $100 \mathrm{ng} / \mathrm{g}$. The high values of the RSD could be attributed to the limited homogeneity of the sludge samples.

It is highlighted that the lower validation performance for the pyrethroids is attributed to their chemical structure and physicochemical properties that make them more prone to gas chromatography in comparison to liquid chromatography. Pyrethroids are typically determined by gas chromatography is soil and sludge $[3,14,16,23,24]$ although HPLC analysis was recently reported for the determination of pyrethroids in cereals [25].

\subsection{Application of the Method}

The concentrations of pesticides found in the tested samples and the \% moisture of the samples are summarized in Table 3. It can be observed that 37 active substances were quantified in total out of the 47 targeted analytes. The highest concentrations found, expressed in dried weight $(\mathrm{dw})$, concern beta cyfluthrin $(3.5 \mathrm{mg} / \mathrm{kg} \mathrm{dw})$, tau-fluvalinate $(3.2 \mathrm{mg} / \mathrm{kg} \mathrm{dw})$, difenoconazole $(1.7 \mathrm{mg} / \mathrm{kg} \mathrm{dw})$, etofenprox $(1.7 \mathrm{mg} / \mathrm{kg} \mathrm{dw})$, cyprodinil $(1.0 \mathrm{mg} / \mathrm{kg} \mathrm{dw})$, phosmet $(0.9 \mathrm{mg} / \mathrm{kg} \mathrm{dw})$, tebuconazole $(0.7 \mathrm{mg} / \mathrm{kg} \mathrm{dw})$, fludioxonil $(0.7 \mathrm{mg} / \mathrm{kg} \mathrm{dw})$, fenoxycarb $(0.6 \mathrm{mg} / \mathrm{kg} \mathrm{dw})$ and boscalid $(0.6 \mathrm{mg} / \mathrm{kg} \mathrm{dw})$. It is noted that these compounds have a moderate to high $\log$ Pow $>2.8$. The concentrations of the rest quantified pesticides ranged between $0.005 \mathrm{mg} / \mathrm{kg} \mathrm{dw}$ (fludioxinil) and $0.434 \mathrm{mg} / \mathrm{kg} \mathrm{dw}$ (fluopyram). Comparison of these results to the results obtained from agro-food sewage sludge samples from Spain [4] shows good agreement in the common analytes detected and quantified which include acetamiprid, carbendazim, imidacloprid, myclobutanil and thiabendazole.

The lower number of pesticides detected and the lower total pesticide load observed in sludge samples No.1 and No.2 comparing to the other three samples could be attributed to the fact that these samples had lower moisture content (22-24\%) and were rather granular with increased particle sizes and thus lower surface/mass ratio, whereas the other samples had high moisture content (72-85\%) and were composed from fine-particulate material with high surface/mass ratio and therefore higher adsorbance capacity. However, practically at the end of such a process all the sludge generated from the washing normally ends up in a collection tank and therefore this is the sludge sample that should be considered as regards the total washing effluent management. 
Table 3. Concentrations of pesticides determined in agro-food industry sludge samples.

\begin{tabular}{|c|c|c|c|c|c|}
\hline Analyte & $\begin{array}{c}\text { Washing Tank } \\
\text { Sample No.1 } \\
(\mathrm{mg} / \mathrm{Kg} \mathrm{dw})\end{array}$ & $\begin{array}{c}\text { Washing Tank } \\
\text { Sample No.2 } \\
(\mathrm{mg} / \mathrm{Kg} \mathrm{dw})\end{array}$ & $\begin{array}{c}\text { Washing Tank } \\
\text { Sample No.3 } \\
(\mathrm{mg} / \mathrm{Kg} \mathrm{dw})\end{array}$ & $\begin{array}{c}\text { Washing Tank } \\
\text { Sample No.4 } \\
(\mathrm{mg} / \mathrm{Kg} \mathrm{dw})\end{array}$ & $\begin{array}{c}\text { Collection Tank } \\
\text { Sample } \\
(\mathrm{mg} / \mathrm{Kg} \mathrm{dw})\end{array}$ \\
\hline Acetamiprid & $\mathrm{ND}(<0.0005)$ & $\mathrm{ND}(<0.0005)$ & 0.078 & 0.042 & 0.008 \\
\hline Azinphos Ethyl & $\mathrm{ND}(<0.01)$ & $\mathrm{ND}(<0.01)$ & $\mathrm{ND}(<0.01)$ & $\mathrm{ND}(<0.01)$ & $\mathrm{ND}(<0.01)$ \\
\hline Beta Cyfluthrin & 0.097 & 0.027 & 3.56 & 3.56 & 3.425 \\
\hline Bifenthrin & ND $(<0.005)$ & $\mathrm{ND}(<0.005)$ & 0.015 & 0.025 & 0.080 \\
\hline Boscalid & $\mathrm{ND}(<0.005)$ & $\mathrm{ND}(<0.005)$ & 0.590 & 0.045 & 0.088 \\
\hline Bupirimate & $\mathrm{ND}(<0.0005)$ & $\mathrm{ND}(<0.0005)$ & $\mathrm{ND}(<0.0005)$ & $\mathrm{ND}(<0.0005)$ & $\mathrm{ND}(<0.0005)$ \\
\hline Carbendazim & $\mathrm{ND}(<0.0005)$ & $\mathrm{ND}(<0.0005)$ & 0.023 & 0.021 & 0.011 \\
\hline Chlorantraniliprole & $\mathrm{ND}(<0.005)$ & $\mathrm{ND}(<0.005)$ & 0.399 & 0.126 & 0.068 \\
\hline Chlorpyrifos-Methyl & $\mathrm{ND}(<0.025)$ & $\mathrm{ND}(<0.025)$ & $\mathrm{ND}(<0.025)$ & $\mathrm{ND}(<0.025)$ & $\mathrm{ND}(<0.025)$ \\
\hline Chlorpyrifos-Ethyl & $\mathrm{ND}(<0.025)$ & $\mathrm{ND}(<0.025)$ & 0.101 & 0.181 & 0.075 \\
\hline Clothianidin & ND $(<0.005)$ & $\mathrm{ND}(<0.005)$ & 0.011 & 0.022 & ND $(<0.005)$ \\
\hline Cyproconazole & $\mathrm{ND}(<0.005)$ & $\mathrm{ND}(<0.005)$ & $\mathrm{ND}(<0.005)$ & $\mathrm{ND}(<0.005)$ & $\mathrm{ND}(<0.005)$ \\
\hline Cyprodinil & $\mathrm{ND}(<0.005)$ & $\mathrm{ND}(<0.005)$ & 1.03 & 0.50 & 0.119 \\
\hline Deltamethrin & $\mathrm{ND}(<0.005)$ & $\mathrm{ND}(<0.005)$ & 0.171 & 0.137 & 0.047 \\
\hline Difenoconazole & 0.010 & 0.010 & 1.69 & 0.38 & 0.672 \\
\hline Etofenprox & $\mathrm{ND}(<0.005)$ & ND $(<0.005)$ & 1.73 & 0.12 & 0.062 \\
\hline Etoxazole & $\mathrm{ND}(<0.005)$ & $\mathrm{ND}(<0.005)$ & 0.066 & 0.011 & 0.026 \\
\hline Fenbuconazole & ND $(<0.005)$ & $\mathrm{ND}(<0.005)$ & $\mathrm{ND}(<0.005)$ & $\mathrm{ND}(<0.005)$ & 0.010 \\
\hline Fenoxycarb & $\mathrm{ND}(<0.005)$ & $\mathrm{ND}(<0.005)$ & 0.575 & 0.210 & 0.043 \\
\hline Fenpyroximate & $\mathrm{ND}(<0.005)$ & $\mathrm{ND}(<0.005)$ & $\mathrm{ND}(<0.005)$ & $\mathrm{ND}(<0.005)$ & ND $(<0.005)$ \\
\hline Flonicamid & $\mathrm{ND}(<0.005)$ & $\mathrm{ND}(<0.005)$ & ND $(<0.005)$ & $\mathrm{ND}(<0.005)$ & ND $(<0.005)$ \\
\hline Fludioxonil & 0.005 & 0.005 & 0.680 & 0.095 & 0.208 \\
\hline Fluopyram & $\mathrm{ND}(<0.0005)$ & $\mathrm{ND}(<0.0005)$ & 0.090 & 0.434 & 0.012 \\
\hline Fluquinconazole & $\mathrm{ND}(<0.005)$ & $\mathrm{ND}(<0.005)$ & ND $(<0.005)$ & 0.021 & 0.012 \\
\hline Tau-Fluvalinate & 0.045 & $\mathrm{ND}(<0.025)$ & 3.17 & 2.05 & 0.706 \\
\hline Fluxapyroxad & $\mathrm{ND}(<0.005)$ & $\mathrm{ND}(<0.005)$ & 0.087 & 0.072 & 0.021 \\
\hline Imazalil & ND $(<0.005)$ & ND $(<0.005)$ & 0.198 & 0.104 & 0.165 \\
\hline Imidacloprid & $\mathrm{ND}(<0.0005)$ & $\mathrm{ND}(<0.0005)$ & $\mathrm{ND}(<0.0005)$ & 0.007 & $\mathrm{ND}(<0.0005)$ \\
\hline Indoxacarb & $\mathrm{ND}(<0.005)$ & $\mathrm{ND}(<0.005)$ & 0.362 & 0.120 & 0.096 \\
\hline Kresoxim Methyl & $\mathrm{ND}(<0.005)$ & $\mathrm{ND}(<0.005)$ & ND $(<0.005)$ & $\mathrm{ND}(<0.005)$ & ND $(<0.005)$ \\
\hline Lambda Cyhalothrin & 0.015 & $\mathrm{ND}(<0.01)$ & 0.471 & 0.305 & 0.338 \\
\hline Methoxyfenozide & $\mathrm{ND}(<0.005)$ & $\mathrm{ND}(<0.005)$ & 0.240 & 0.041 & 0.037 \\
\hline Myclobutanil & $\mathrm{ND}(<0.005)$ & 0.013 & 0.294 & 0.198 & 0.043 \\
\hline Phosalone & $\mathrm{ND}(<0.005)$ & $\mathrm{ND}(<0.005)$ & $\mathrm{ND}(<0.005)$ & $\mathrm{ND}(<0.005)$ & $\mathrm{ND}(<0.005)$ \\
\hline Phosmet & $\mathrm{ND}(<0.005)$ & $\mathrm{ND}(<0.005)$ & 0.906 & 0.114 & 0.012 \\
\hline Propargite & $\mathrm{ND}(<0.005)$ & $\mathrm{ND}(<0.005)$ & 0.019 & 0.034 & $\mathrm{ND}(<0.005)$ \\
\hline Pyraclostrobin & $\mathrm{ND}(<0.005)$ & $\mathrm{ND}(<0.005)$ & 0.059 & 0.023 & 0.005 \\
\hline Pyrimethanil & $\mathrm{ND}(<0.005)$ & $\mathrm{ND}(<0.005)$ & 0.010 & 0.005 & ND $(<0.005)$ \\
\hline Pyriproxyfen & $\mathrm{ND}(<0.005)$ & $\mathrm{ND}(<0.005)$ & 0.087 & 0.090 & $\mathrm{ND}(<0.005)$ \\
\hline Spirotetramat & $\mathrm{ND}(<0.005)$ & $\mathrm{ND}(<0.005)$ & $\mathrm{ND}(<0.005)$ & $\mathrm{ND}(<0.005)$ & $\mathrm{ND}(<0.005)$ \\
\hline Tebufenozide & $\mathrm{ND}(<0.005)$ & $\mathrm{ND}(<0.005)$ & 0.354 & 0.099 & 0.132 \\
\hline Tebuconazole & $\mathrm{ND}(<0.005)$ & $\mathrm{ND}(<0.005)$ & 0.752 & 0.312 & 0.111 \\
\hline Thiacloprid & ND $(<0.0005)$ & 0.002 & 0.243 & 0.385 & 0.063 \\
\hline Thiabendazole & 0.007 & 0.005 & 0.571 & 0.218 & 0.505 \\
\hline Thiamethoxam & $\mathrm{ND}(<0.005)$ & $\mathrm{ND}(<0.005)$ & $\mathrm{ND}(<0.005)$ & 0.099 & $\mathrm{ND}(<0.005)$ \\
\hline Thiophanate Methyl & $\mathrm{ND}(<0.005)$ & $\mathrm{ND}(<0.005)$ & $\mathrm{ND}(<0.005)$ & $\mathrm{ND}(<0.005)$ & $\mathrm{ND}(<0.005)$ \\
\hline Trifloxystrobin & ND $(<0.005)$ & ND $(<0.005)$ & 0.309 & 0.171 & 0.010 \\
\hline $\begin{array}{l}\text { Total pesticide load } \\
\text { per sludge sample } \\
(\mathrm{mg} / \mathrm{Kg} \mathrm{dw})\end{array}$ & 0.2 & 0.1 & 19.0 & 10.4 & 7.2 \\
\hline $\begin{array}{l}\text { Number of } \\
\text { pesticides detected } \\
\text { per sludge sample }\end{array}$ & 6 & 6 & 33 & 36 & 31 \\
\hline Moisture \% & 24 & 22 & 85 & 73 & 72 \\
\hline
\end{tabular}




\section{Conclusions}

The present work described the development and validation of an LC-ESI (+/-)-MS/MS triple quadrupole method for the determination of 47 pesticides in sludge samples after QuEChERS sample preparation. During the optimization of the method, it was demonstrated that both dispersive solid phase extraction steps of QuEChERS are required for all the target analytes, while the final solvent of the measured solutions was found to significantly affect the sensitivity of analytes with low and high logPow. In addition, the stepwise optimization followed of the LC-ESI-MS/MS parameters, which included, among others, optimization of the drying gas temperature and division of the chromatographic run in segments, led to the development of a reliable, fast, low cost analytical method, using common instrumentation, that can serve for the monitoring of 47 pesticides of different chemical groups, in sludge, with the possibility of adding more active substances in the method. Along with the incorporation of more pesticide active ingredients and their metabolites, other impurities present in the plant protection products and other xenobiotics may be incorporated in this method.

The method was applied to five sludge samples obtained from an agro-food process with the aim to determine the concentration levels of the pesticides in the sludge. This knowledge can be taken into consideration for appropriate handling of this kind of waste at industry scale in a sustainable way. It is noted that although sewage sludge can be characterized as dangerous waste depending on its content in heavy metals according to European legislation [26], currently there is no legislation characterizing sewage sludge as a dangerous waste in terms of its pesticides' concentration. Although, the Food and Agricultural Organization of the United Nations (FAO) has made available a reference manual for assessing soil contamination by pesticides which aims to help the user determine if pesticide spills have caused soil or groundwater contamination and, if so, whether or not that contamination implies risks for human health [27], further research is required in order to establish standards for the pesticides' concentration in sludge.

Supplementary Materials: The following are available online, Table S1: Target compounds' molecular weight, formula and structure (ordered by retention time, RT), function and partition coefficient pKow (pH 7, $20^{\circ} \mathrm{C}$ ), Table S2: Number of SRMs included in each time-segment, dwell time of each transition, total scan time of each time-segment and the drying gas temperature set for each timesegment, Table S3: Matrix effect on the signal of late eluting analytes obtained in Fraction A and B (RT: Retention time), Table S4: Linear regression equations, $\mathrm{y}=\mathrm{a} \times \mathrm{C}+\mathrm{b}$, of the matrix-matched curves where $y$ is the ratio of the Peak area of the analyte/Peak area of the internal standard and C, the concentration in ng/g, Figure S1: (i). Quantification (SRM1) and confirmation (SRM2) chromatograms of analytes flonicamid-clothianidin determined in Fraction C of sludge sample fortified at $10 \mathrm{ng} / \mathrm{g}$, (ii). Quantification (SRM1) and confirmation (SRM2) chromatograms of analytes imidaclopridchloratranilipole determined in Fraction C of sludge sample fortified at $10 \mathrm{ng} / \mathrm{g}$, (iii). Quantification (SRM1) and confirmation (SRM2) chromatograms of analytes boscalid-methoxyfenozide determined in Fraction C of sludge sample fortified at $10 \mathrm{ng} / \mathrm{g}$, (iv). Quantification (SRM1) and confirmation (SRM2) chromatograms of analytes bupirimate-fluopyram determined in Fraction C of sludge sample fortified at $10 \mathrm{ng} / \mathrm{g}$, (v). Quantification (SRM1) and confirmation (SRM2) chromatograms of analytes fenbuconazole-tebuconazole determined in Fraction C of sludge sample fortified at $10 \mathrm{ng} / \mathrm{g}$, (vi). Quantification (SRM1) and confirmation (SRM2) chromatograms of analytes triphenyl-phosphate (I.S)-difenoconazole determined in Fraction C of sludge sample fortified at $10 \mathrm{ng} / \mathrm{g}$, (vii). Quantification (SRM1) and confirmation (SRM2) chromatograms of analyte Fludioxonil determined in Fraction C of sludge sample fortified at $10 \mathrm{ng} / \mathrm{g}$, in negative polarity, Figure S2: (i). Quantification (SRM1) and Confirmation (SRM2) chromatograms of analytes imazalil-triphenyl-phosphate (I.S) determined in Fraction B of sludge sample fortified at $10 \mathrm{ng} / \mathrm{g}$, (ii). Quantification (SRM1) and confirmation (SRM2) chromatograms of analytes phosalone-indoxacarb determined in Fraction B of sludge sample fortified at $10 \mathrm{ng} / \mathrm{g}$, (iii). Quantification (SRM1) and confirmation (SRM2) chromatograms of analytes pyriproxyfen-b-cyfluthrin determined in Fraction B of sludge sample fortified at 10-200 ng/g, (iv). Quantification (SRM1) and confirmation (SRM2) chromatograms of analytes fenpyroximateetofenprox determined in Fraction B of sludge sample fortified at $10-50 \mathrm{ng} / \mathrm{g}$, (v). Quantification 
(SRM1) and confirmation (SRM2) chromatograms of analyte bifenthrin determined in Fraction B of sludge sample fortified at $10 \mathrm{ng} / \mathrm{g}$.

Author Contributions: Conceptualization E.M.; methodology, N.C.M. and G.B.; validation, N.C.M. and G.B.; resources, E.M. and K.L.; data curation, N.C.M. and G.B.; writing-original draft preparation, N.C.M.; writing-review and editing, G.B., E.K., E.M., K.L. and N.C.M.; visualization, N.C.M.; project administration, E.M.; funding acquisition, E.M. All authors have read and agreed to the published version of the manuscript.

Funding: This research was funded by LIFE17 ENV/GR/000387_LIFE PureAgroH20 Project.

Institutional Review Board Statement: Not applicable.

Informed Consent Statement: Not applicable.

Data Availability Statement: Not applicable.

Acknowledgments: The authors would like to express their acknowledgment to E. Zafeiraki for the assistance in sludge sampling and A. Marousopoulou and M. Kapsalou for their technical support.

Conflicts of Interest: The authors declare no conflict of interest.

Sample Availability: Samples of the compounds are not available from the authors.

\section{References}

1. Tadeo, J.L.; Sánchez-Brunete, C.; Albero, B.; García-Valcárcel, A.I. Determination of Pesticide Residues in Sewage Sludge: A Review. J. AOAC Int. 2010, 93, 1692-1702. [CrossRef]

2. Helaleh, M.I.H.; Al-Omair, A.; Ahmed, N.; Gevao, B. Quantitative determination of organochlorine pesticides in sewage sludges using soxtec, soxhlet and pressurized liquid extractions and ion trap mass-mass spectrometric detection. Anal. Bioanal. Chem. 2005, 382, 1127-1134. [CrossRef]

3. Soares, K.L.; Cerqueira, M.B.R.; Caldas, S.S.; Primel, E.G. Evaluation of alternative environmentally friendly matrix solid phase dispersion solid supports for the simultaneous extraction of 15 pesticides of different chemical classes from drinking water treatment sludge. Chemosphere 2017, 182, 547-554. [CrossRef] [PubMed]

4. Ponce-Robles, L.; Rivas, G.; Esteban, B.; Oller, I.; Malato, S.; Aguera, A. Determination of pesticides in sewage sludge from an agro-food industry using QuEChERS extraction followed by analysis with liquid chromatography-tandem mass spectrometry. Anal. Bioanal. Chem. 2017, 409, 6181-6193. [CrossRef]

5. Masiá, A.; Vásquez, K.; Campo, J.; Picó, Y. Assessment of two extraction methods to determine pesticides in soils, sediments and sludges. Application to the Túria River Basin. J. Chromatogr. A 2015, 1378, 19-31. [CrossRef]

6. Benedetti, B.; Majonea, M.; Cavalierea, C.; Montonea, C.M.; Fatone, F.; Frison, N.; Laganà, A.; Capriotti, A.L. Determination of multi-class emerging contaminants in sludge and recovery materials from waste water treatment plants: Development of a modified QuEChERS method coupled to LC-MS/MS. Microchem. J. 2020, 155, 104732. [CrossRef]

7. Anastassiades, M.; Lehotay, S.J.; Tajnbaher, D.; Schenck, F.J.J. Fast and Easy Multiresidue Method Employing Acetonitrile Extraction/Partitioning and "Dispersive Solid-Phase Extraction" for the Determination of Pesticide Residues in Produce. J. AOAC Int. 2003, 86, 412-431. [CrossRef] [PubMed]

8. Lehotay, S.J.; Majors, R.E.; Anastassiades, M. The QuEChERS Revolution. LCGC Eur. 2010, 23, 418-429.

9. Silva, V.; Mol, H.G.J.; Zomer, P.; Tienstra, M.; Ritsema, C.J.; Geissen, V. Pesticide residues in European agricultural soils-A hidden reality unfolded. Sci. Total Environ. 2019, 653, 1532-1545. [CrossRef] [PubMed]

10. Lesueur, C.; Gartner, M.; Mentler, A.; Fuerhacker, M. Comparison of four extraction methods for the analysis of 24 pesticides in soil samples with gas chromatography-mass spectrometry and liquid chromatography-ion trap-mass spectrometry. Talanta 2008, 75, 284-293. [CrossRef]

11. Asensio-Ramos, M.; Hernández-Borges, J.; Ravelo-Pérez, L.M.; Rodríguez-Delgado, M.A. Evaluation of a modified QuEChERS method for the extraction of pesticides from agricultural, ornamental and forestal soils. Anal. Bioanal. Chem. 2010, 396, $2307-2319$. [CrossRef]

12. Caldas, S.S.; Bolzan, C.M.; Cerqueira, M.B.; Tomasini, D.; Furlong, E.B.; Fagundes, C.; Primel, E.G. Evaluation of a Modified QuEChERS Extraction of Multiple Classes of Pesticides from a Rice Paddy Soil by LC-APCI-MS/MS. J. Agric. Food Chem. 2011, 59, 11918-11926. [CrossRef] [PubMed]

13. Fernandes, V.C.; Domingues, V.F.; Mateus, N.; Delerue-Matos, C. Multiresidue pesticides analysis in soils using modified QuEChERS with disposable pipette extraction and dispersive solid-phase extraction. J. Sep. Sci. 2013, 36, 376-382. [CrossRef] [PubMed]

14. Pszczolinska, K.; Michel, M. The QuEChERS Approach for the Determination of Pesticide Residues in Soil Samples: An Overview. J. AOAC Int. 2016, 99, 1403-1414. [CrossRef] [PubMed] 
15. Homazava, N.; Aquillon, C.G.; Vermeirssen, E.; Werner, I. Simultaneous multi-residue pesticide analysis in soil samples with ultra-high-performance liquid chromatography-tandem mass spectrometry using QuEChERS and pressurised liquid extraction methods. Inter. J. Environ. Anal. Chem. 2014, 94, 1085-1099. [CrossRef]

16. Chai, L.K.; Elie, F.; Jinang, C. Determination of 24 pesticides residues in mineral and peat soils by modified QuEChERS method and gas chromatography. Inter. J. Environ. Anal. Chem. 2014, 94, 519-530. [CrossRef]

17. Hrouzková, S.; Szarka, A. Development of a Modified QuEChERS Procedure for the Isolation of Pesticide Residues from Textile Samples, Followed by GC-MS Determination. Separations 2021, 8, 106. [CrossRef]

18. IUPAC Pesticides Properties DataBase-AERU. Available online: http://sitem.herts.ac.uk/aeru/iupac/ (accessed on 15 July 2021).

19. Compendium of Pesticide Common Names. Available online: https:// pesticidecompendium.bcpc.org (accessed on 15 July 2021 ).

20. CEN. Foods of Plant Origin-Determination of Pesticide Residues Using GC-MS and/or LC-MS/MS Following Acetonitrile Extraction/Partitioning and Clean-Up by Dispersive SPE-QuEChERS-Method; European Standard EN 15662:2008. Available online: https:/ / www.en-standard.eu/csn-en-15662-foods-of-plant-origin-multimethod-for-the-determination-of-pesticideresidues-using-gc-and-lc-based-analysis-following-acetonitrile-extraction-partitioning-and-clean-up-by-dispersive-spemodular-quechers-method/ (accessed on 15 July 2021).

21. Maragou, N.C.; Thomaidis, N.S.; Koupparis, M.A. Optimization and comparison of ESI and APCI LC-MS/MS methods: A case study of Irgarol 1051, Diuron, and their degradation products in environmental samples. J. Am. Soc. Mass Spectrom. 2011, 22, 1826-1838. [CrossRef] [PubMed]

22. European Commission. Guidance Document on Pesticide Analytical Methods for Risk Assessment and Post-approval Control and Monitoring Purposes; SANTE/2020/12830, Rev.1. 24 February 2021. Available online: https://ec.europa.eu/food/system/ files/2021-02/pesticides_mrl_guidelines_2020-12830.pdf (accessed on 7 November 2021).

23. Rodríguez-Liébana, J.A.; Mingorance, M.D.; Peña, A. Sorption of hydrophobic pesticides on a Mediterranean soil affected by wastewater, dissolved organic matter and salts. J. Environ. Manag. 2011, 92, 650-654. [CrossRef]

24. Fernandez-Alvareza, M.; Llompart, M.; Lamasa, J.P.; Loresa, M.; Garcia-Jares, C.; Cela, R.; Dagnac, T. Simultaneous determination of traces of pyrethroids, organochlorines and other main plant protection agents in agricultural soils by headspace solid-phase microextraction-gas chromatography. J. Chromatogr. A 2008, 1188, 154-163. [CrossRef] [PubMed]

25. Wu, B.; Guo, Z.; Li, X.; Huang, X.; Teng, C.; Chen, Z.; Jing, X.; Zhao, W. Analysis of pyrethroids in cereals by HPLC with a deep eutectic solvent-based dispersive liquid-liquid microextraction with solidification of floating organic droplets. Anal. Methods 2021, 13, 636. [CrossRef]

26. Council Directive of 12 June 1986 on the protection of the environment, and in particular of the soil, when sewage sludge is used in agriculture, 86/278/EEC. Off. J. Eur. Communities. 1986. Available online: https://www.legislation.gov.uk/eudr/1986/278 / contents (accessed on 15 July 2021).

27. Food and Agriculture Organization of the United Nations Rome (c FAO 2000. Assessing Soil Contamination: A Reference Manual. Available online: http:/ / www.fao.org/3/x2570e/X2570E00.htm\#TOC (accessed on 15 July 2021). 